Revista de Metalurgia 51(3)

July-September 2015, e048

ISSN-L: 0034-8570

doi: http://dx.doi.org/10.3989/revmetalm.048

\title{
The intermetallic bonding between a ring carrier and aluminum piston alloy
}

\author{
Srećko Manasijevića ${ }^{\mathrm{a} \bowtie}$, Natalija Dolićb ${ }^{\mathrm{b}}$, Mile Djurdjevic ${ }^{\mathrm{c}}$, Nataša Mišića ${ }^{\mathrm{a}}$, Novica Davitkov ${ }^{\mathrm{d}}$ \\ ${ }^{\mathrm{a}}$ Lola Institute, Kneza Višeslava 70a, 11000 Belgrade, Serbia \\ ${ }^{b}$ University of Zagreb, Faculty of Metallurgy, Aleja narodnih heroja 3, 44103 Sisak, Croatia \\ ${ }^{c}$ Nemak Europe, Zeppelinstraße 24, 4030 Linz, Austria \\ dUniversity of Belgrade, Technical Faculty in Bor, 12 Vojske Jugoslavije, 19201 Bor, Serbia \\ Corresponding author: srecko.manasijevic@li.rs
}

Submitted: 11 December 2014; Accepted: 19 May 2015; Available On-line: 22 September 2015

\begin{abstract}
This paper presents the results of investigating the formation of intermetallic bond between a ring carrier and aluminum piston alloy. The ring carrier is made of austenitic cast iron (Ni-Resist) in order to increase the wear resistance of the first ring groove and applied in highly loaded diesel engines. Metallographic examination of the quality of alfin bond was done. A metallographic investigation using an optical microscope in combination with the SEM/EDS analysis of the quality of the intermetallic bonding layer was done. The test results show that can be made successfully as well as the formation of metal connection (alfin bond) between the ring carrier and aluminum piston alloy.
\end{abstract}

KEYWORDS: Alfin bond; Intermetallic bond; Ni-Resist; Piston alloys; Ring carrier

Citation / Cómo citar este artículo: Manasijević, S., Dolić, N., Djurdjevic, M., Mišić, N., Davitkov, N. (2015) “The intermetallic bonding between a ring carrier and aluminum piston alloy". Rev. Metal. 51(3): e048. doi: http://dx.doi. org/10.3989/revmetalm.048.

RESUMEN: La unión intermetálica entre el portasegmento y la aleación de aluminio del pistón. El artículo presenta los resultados de la investigación sobre la formación de una unión intermetálica entre el portasegmento y la aleación de aluminio del pistón. El portasegmento es una fundición de hierro austenítico (Ni-Resist) con el fin de aumentar la resistencia al desgaste de la unión Al-fin del primer segmento y se utiliza en motores diésel altamente cargados. Se realizó un examen metalográfico de la unión intermetálica, mediante un microscopio óptico en combinación con SEM/EDS. Los satisfactorios resultados obtenidos muestran la formación de contacto metálico (unión Al-fin del primer segmento) entre el portasegmento y la aleación de aluminio del pistón.

PALABRAS CLAVE: Aleaciones del pistón; Ni-Resist; Portasegmento (aro); Unión intermetálica

Copyright: (C) 2015 CSIC. This is an open-access article distributed under the terms of the Creative Commons Attribution-Non Commercial (by-nc) Spain 3.0 License.

\section{INTRODUCTION}

Pistons are made mostly of aluminum alloys (Al-Si-Cu-Ni-Mg), which represent a special group of industrial alloys that are used in the automotive industry due to a combination of good casting and mechanical properties (Manasijevic et al., 2009), high strength at elevated temperatures (e.g., up to $350{ }^{\circ} \mathrm{C}$ ) and also resistance to sudden temperature changes (Belov et al., 2005; Manasijevic et al., 2009; Manasijevic, 2012; Manasijevic et al., 2013). Different types of piston alloys contain various amounts of major and minor alloying elements. The usual content of alloying elements is: $11-23 \mathrm{wt} . \% \mathrm{Si}$, 
0.5-3 wt. \% Ni, 0.5-5.5 wt.\% Cu, 0.6-1.3 wt.\% Mg, up to $1.0 \mathrm{wt} . \% \mathrm{Fe}$ and up to $1 \mathrm{wt} . \% \mathrm{Mn}$ (Belov et al., 2005; Manasijevic et al., 2009; Manasijevic, 2012; Manasijevic et al., 2013). The mechanical properties of aluminum piston alloys are defined by their micro and macro structures.

In order to keep up with all loads of aggressive environments, mechanical and thermal loads, the pistons materials must meet the following requirements (Manasijevic, 2012):

- low density (to reduce the load on the piston rod),

- low coefficient of thermal expansion (because the thermal expansion (of the cylinder engine is twice lower than that of aluminum),

- higher thermal conductivity (to ensure rapid heat removal from the combustion chamber),

- $\quad$ surface hardness (in order to increase the wear resistance),

- high compactness of the material (because the penetration of gas into the pores and micro cracks leads to volume changes and damage to the piston engine),

- corrosion stability in the middle of hot corrosive gases (because it could otherwise lead to the rapid destruction of the piston), good workability (due to rigorous structural requirements for microgeometry of the cylinder assembly) and low price.

Depending on the engine type and operating conditions, there are different design solutions of pistons (Manasijevic, 2012): mono metallic aluminum pistons, pistons with ring carrier, pistons with cooling channel, pistons with cooling channel and ring carrier, pistons with controlled expansion, pistons with controlled spreading and ring carrier, pistons with iron coating, forged pistons, split pistons, pistons with the first groove reinforced, pistons with undulating mantle etc.

Mono metal aluminum pistons are made of aluminum alloy only, since the environment in which they are used does not require any additional elements. In the past, cast mono metal aluminum pistons were used for engine cylinder block of cast iron. Today, this type of piston is used in Otto engines with aluminum cylinder with relatively low-loaded automotive diesel engines (effective pressure up to 6.5 bar) with indirect injection (Manasijevic, 2012). Although the thermal load of the piston and the load of piston notches are higher in diesel engines, the shortcomings can be compensated for by using hypereutectic aluminum alloy with good wear resistance in pistons. Another positive feature of this alloy is small thermal expansion (Manasijevic, 2012).

In order to meet the requirements for lower fuel consumption, mean effective pressure of diesel engines for commercial vehicles is growing. These are the engines that must be designed to withstand high loads for long periods of work, especially in the critical areas of the piston that are thermally very loaded. Today's modern aluminum pistons with ring carrier can meet these requirements. The ring carrier is specially designed for formation of the first piston ring groove in highly loaded diesel engines. Wear-resisting piston ring carrier can reduce the temperature at piston head, increase the resistance of piston to wearing and dramatically increase the lifetime of the piston (Worden et al., 2000; Viala et al., 2002; Belov et al., 2005; Engine Australia, 2012; Manasijevic, 2012). In the meantime, it can also improve the air-tightness of the piston in the cylinder, increase the efficiency of combustion, reduce emission and air pollution and contribute to the environment. The ring carrier must have a very similar coefficient of thermal expansion with aluminum piston alloy. If this were not the case, rapid and massive temperature fluctuations experienced in the piston crown would result in the piston alloy and the Alfin insert expanding and contracting at very different rates and values. Manufactures use very different shapes of the ring carrier to help lock it into the casting. The real strength of the insert in the piston is the result of a molecular or atomic bond between the insert and piston materials. Producers also often use other improvements: cooled ring carrier, insertion of pin bore bushings, etc. The ring carrier is ring-shaped with different cross sections. Most often, its outside diameter is $70-200 \mathrm{~mm}$ and its inner diameter is $50-180 \mathrm{~mm}$ (Manasijevic, 2012). The ring carrier is produced by centrifugal casting.

This would cause failure of the bond between the two materials. The Alfin process is a method for preparing a ferrous surface for intermetallic bonding. The alfin bonding process is commonly used to bond a non-ferrous Al alloy and a ferrous alloy-such as aluminum diesel engine pistons and Ni-Resist ring carriers-directly together. It is well known that cast iron contains carbon as a result of the casting process. During the piston casting, the ring carrier is soaked by the Alfin bond process, which results in a strong connection with the piston material. During this process, an intermetallic layer composed of $\mathrm{Fe}_{\mathrm{x}} \mathrm{Al}_{\mathrm{y}}$ is formed on the border between the two different materials by the diffusion of atoms (Willcox, 2000; Worden et al., 2000; Belov et al., 2005; Acar et al., 2010; Manasijevic, 2012).

The formation of an intermetallic bond layer is a very complex process. In the manufacturing plant, the formed intermetallic bond may also be damaged during the machining process. The intermetallic bond between the ring carrier and piston must be able to withstand prolonged exposure to the high-pressure and temperature environment of the diesel engine. Weak cohesion may result in the debonding of the ring carrier. This debonding causes devastating damage to the piston while the engine is in service. For the aforementioned reasons these processes should 
be controlled precisely. Ultrasonic inspection techniques are widely used in the industry where a nondestructive evaluation is used for quality testing of alfin bond between ring carrier and piston (Acar et al., 2010; Manasijevic, 2012). The manufacturers of ultrasonic devices have special ultrasonic instruments with piston inspection software.

The aim of this paper is examine to formation of metal connection (alfin bond) between the ring carrier and aluminum piston alloy and identification of formed intermetallic phase $\mathrm{Fe}_{\mathrm{x}} \mathrm{Al}_{\mathrm{y}}$.

\section{MATERIALS AND METHODS}

The tests were performed on the $\varnothing 89 \mathrm{~mm}$ piston with a cooling channel for diesel engine type OM604 with turbocharger. A CAD model of the piston casting (with a cross-section of the investigated) is shown in Fig. 1. The mass of the piston casting with a pouring system and feeder is $1275 \mathrm{~g}$ and the mass of the piston cast is $868 \mathrm{~g}$.

Piston alloys (Table 1) of approximately eutectic composition were used to analyze the formation of alfin bond with a ring carrier.

Chemical composition and balance hardness (HBS 120-160 (Manasijevic, 2012), in this case 140-150) according to well-known manufacturers Mahle, KS, Federal Mogul and local piston manufacturer Serbian Concern Petar Drapsin-Mladenovac (PDM), Serbia (Manasijevic, 2012), are given in Table 2. Ring carrier materials are melted in induction furnaces at $1450{ }^{\circ} \mathrm{C}$. Then the final shape of the ring carrier is produced by a centrifugal casting machine. These ring carriers are placed in the piston mold and the molten piston material is poured in. The most important thing is that the Ni-Resist die cast material (ferrous) must be bonded with a nonferrous piston material during the casting of the piston. The insertion of the ring carrier in the piston mold lasts 5 seconds while the time to the total soaking of the ring carrier is 25 seconds. The piston mold temperature is $245-275^{\circ} \mathrm{C}$.

Melting of alloy for piston cast was performed in tub-like electro-resistant inclined furnace, type RIO 750 , with power of $80 \mathrm{~kW}$ and capacity of $120 \mathrm{~kg} \mathrm{~h}^{-1}$. Preparation of Al-alloy was performed in electroresistant muffler-like furnace with black lead muffler, type RIO 250 with power of $85 \mathrm{~kW}$. For improving mechanical properties, during preparation, the piston casting was exposed to melt treatment processes (refining, modification and degasification). All three operations were performed at $725 \pm 5^{\circ} \mathrm{C}$. The temperature of the melt was measured using a $\mathrm{Ni}-\mathrm{Cr}-\mathrm{Ni}$ digital pyrometer.

The casting of the investigated pistons was performed on a semi-automatic machine subject to the manufacturing conditions in the PDM, Serbia. The ring carrier was inserted manually. The machine has an automatic cycle operation. Casting machines tilt by 20 to 0 degrees during casting (in this case, they started tilting 7 seconds after the start of casting).

An optical microscope (Olympus GX51) with a magnification of up to $1000 \mathrm{X}$ was used for visualization and collecting the data for determining the microstructure of the material. Samples for metallographic analysis were acquired by an Olympus DP70 color digital camera (12.5 megapixel resolution). Metallographic samples were cut out from the piston, (a)

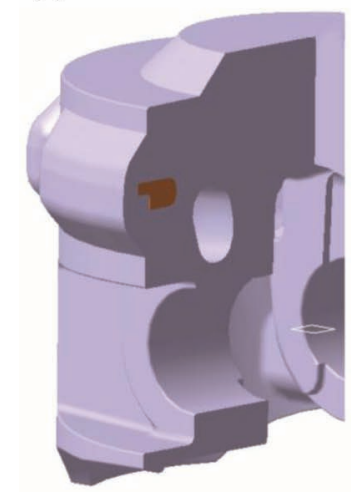

(b)

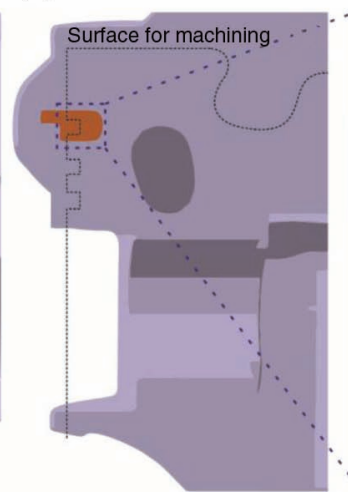

(c)

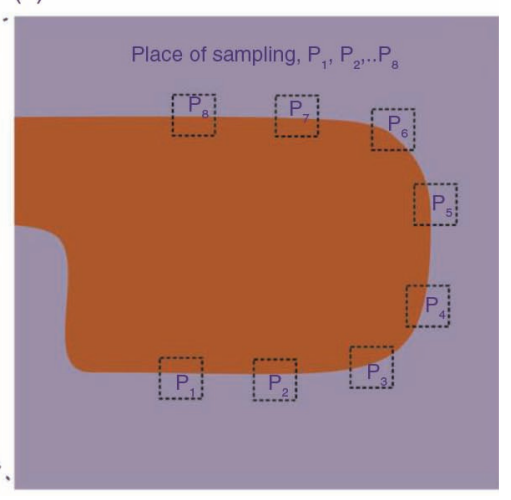

Figure 1. CAD model of cast piston.

TABLE 1. Nominal chemical composition of the experimental alloy

\begin{tabular}{lcccccccccccc}
\hline & \multicolumn{10}{c}{ Chemical composition (wt.\%) } \\
\cline { 2 - 12 } Alloy & $\mathbf{S i}$ & $\mathbf{C u}$ & $\mathbf{N i}$ & $\mathbf{M g}$ & $\mathbf{F e}$ & $\mathbf{M n}$ & $\mathbf{C r}$ & $\mathbf{T i}$ & $\mathbf{Z r}$ & $\mathbf{V}$ & $\mathbf{A l}$ \\
\hline AlSi13Cu4Ni2Mg & 13.05 & 3.80 & 2.01 & 0.90 & 0.52 & 0.19 & 0.09 & 0.07 & $\approx 0.03$ & $\approx 0.01$ & residual \\
\hline
\end{tabular}


TABLE 2. Chemical composition of the ring carrier (wt.\%)

\begin{tabular}{lcccccccc}
\hline $\mathbf{N i}$ & $\mathbf{C u}$ & $\mathbf{C}$ & $\mathbf{C r}$ & $\mathbf{S i}$ & $\mathbf{M n}$ & $\mathbf{S}$ & $\mathbf{P}$ & $\mathbf{F e}$ \\
\hline 15.25 & 6.09 & 2.88 & 2.21 & 1.89 & 1.23 & - & - & residual \\
\hline
\end{tabular}

polished and electrolytically etched in a HF reagent for 15 seconds. The samples were observed under a scanning electron microscope (SEM) TESKAN VEGA TS5136LS equipped with energy dispersive spectrometer (EDS, Bruker).

\section{RESULTS AND DISCUSSION}

In this case, austenitic cast iron with lamellar graphite (Ni-Resist, Fig. 2a) was used to produce the ring carrier. The microstructure of the ring carrier resulted in graphite distribution in austenite: ASTM type A or B, size 4-6. This ring carrier is observed to embed with the Al alloy after solidification.

After casting and machining (Fig. 2b), the ring carrier was degreased by ultrasound and held in the alloy casting (Fig. 2c) at the melt temperature for a certain time. The ring carrier was heated at $760-780^{\circ} \mathrm{C}$ (6.5 minutes), uniformly coated with a thin liquid piston alloy layer (30-100 $\mu \mathrm{m}$ thick) and pulled out of the alloy bath; in a second step, the hot aluminized ring carrier was immediately placed in a preheated metallic mold and fresh liquid piston alloy was poured into that mold. Afterwards, the ring carrier was inserted using specially designed gripper in the mold. It then took about 10 seconds for filling the mold, a period of time during which a maximum temperature of $700-720^{\circ} \mathrm{C}$ was reached at the insert/alloy interface and 110 seconds more for complete solidification of the casting which was then air-cooled to room temperature.

Figure 3a shows the macrostructure of the piston cross section, where successful alfin bond between the ring carrier and the piston alloy is shown. Then the piston is subjected to machining to create the final shape (Fig. 3b). In Fig 3a and Fig 3b visually see that a good connection has been established between the ring carrier and piston alloy. The thickness of the diffusion layer was measured (Sample 1 shown in Fig. 3d).

The alfin bond analysis was made at the points indicated in Fig. 1. The results show that the thickness of the diffusion layer formed in the piston alloy is in the range from 14.60-36.19 $\mu \mathrm{m}$ (Sample 1,
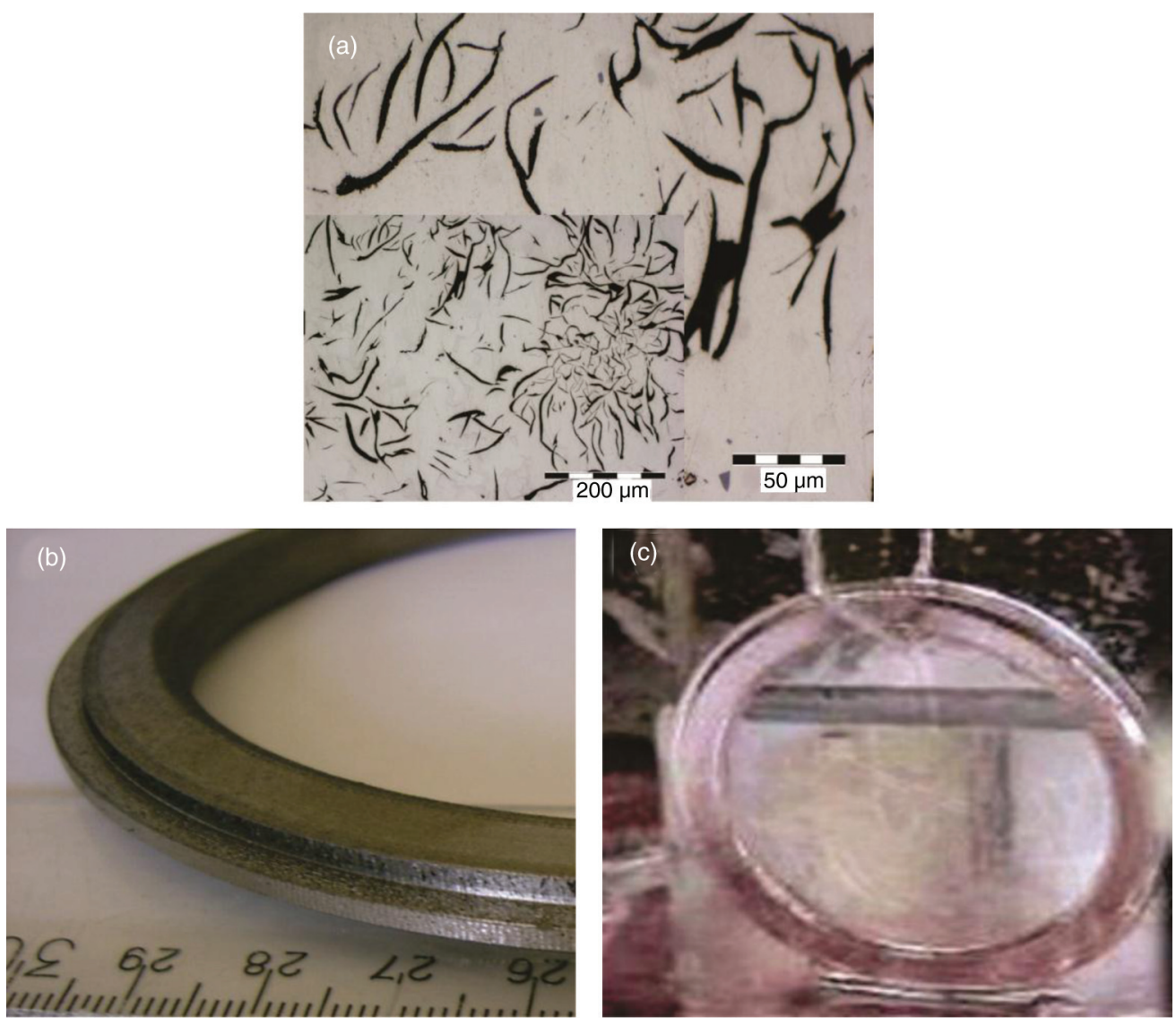

FIGURE 2. The ring carrier: a) microstructure; b) after machining and c) preparation in alloy melt. 

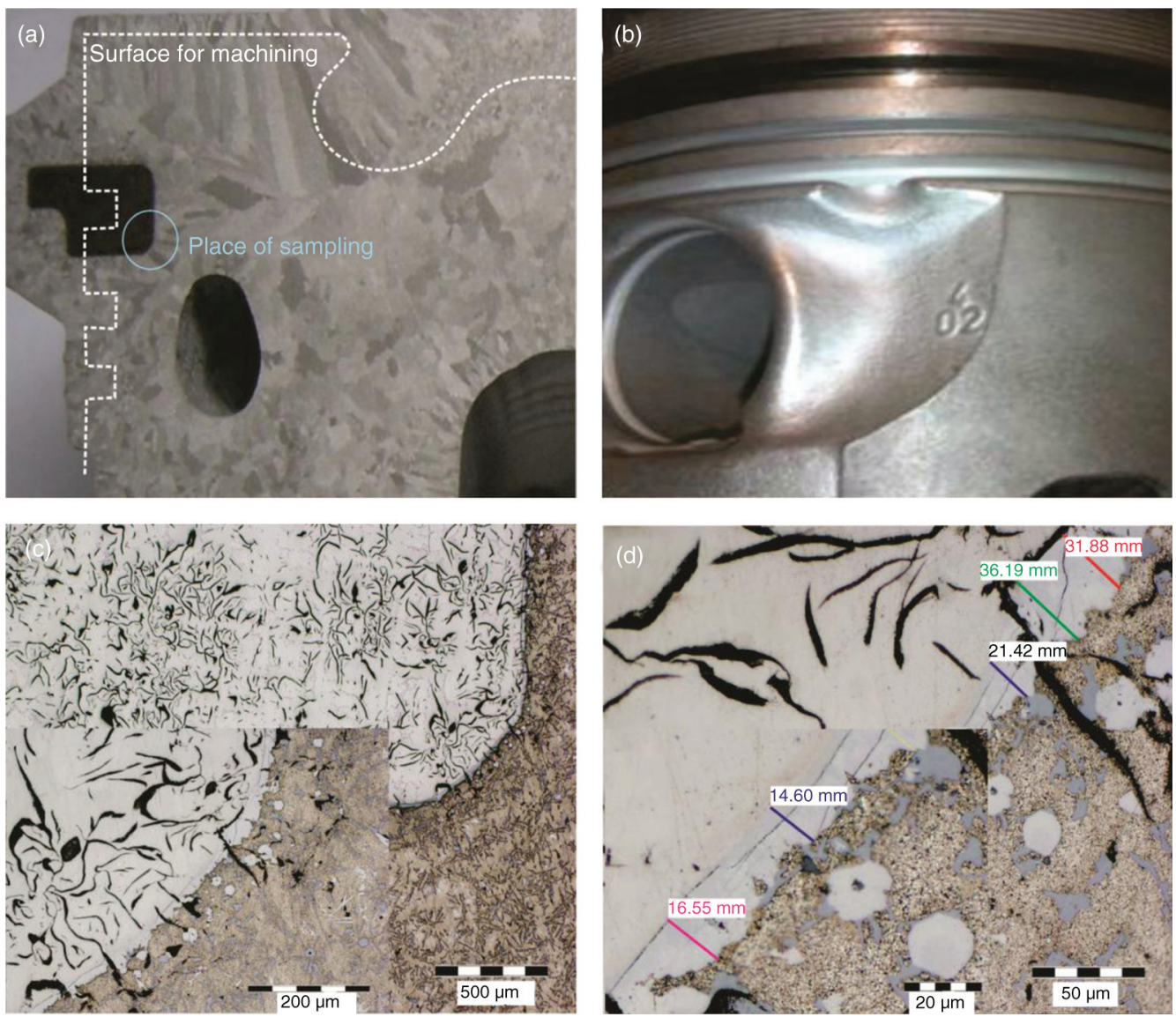

FIgURE 3. Alfin bond between the ring carrier and piston alloy: a) macrostructure of the cast; b) piston machined; c) 50X and 100x and d) 500X.

Sample 2 and Sample 3) see Fig. 4. The average is $27.83 \mu \mathrm{m}$ for Sample 1, $24.58 \mu \mathrm{m}$ for Sample 2 and $25.61 \mu \mathrm{m}$ for Sample 3. The diffusion layer thickness

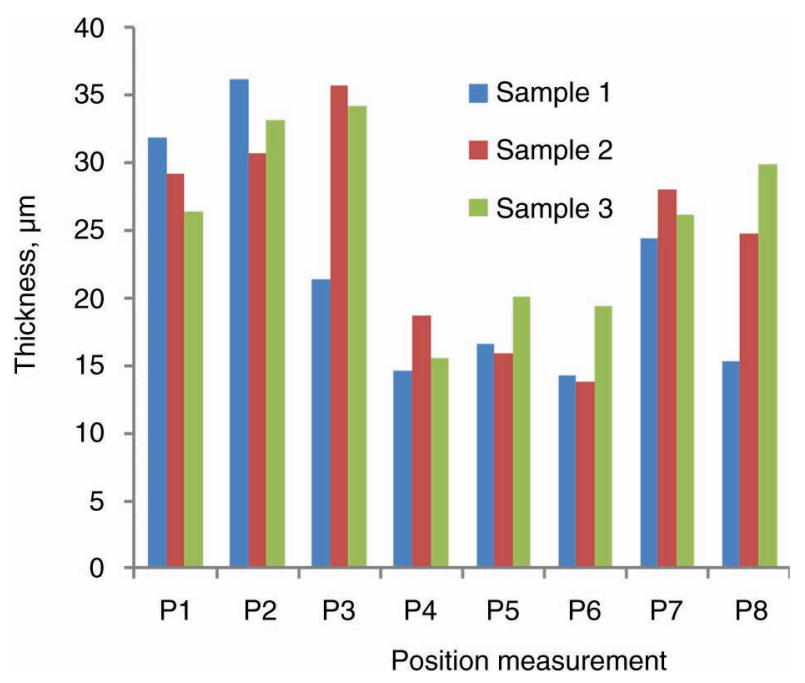

FIgURE 4. The thickness of the diffusion layer. allowed by international manufacturers of pistons for diesel engines is $10-70 \mu \mathrm{m}$ (Manasijevic, 2012).

The microstructure of the aluminum piston alloy have different structures depending on the content of silicon and other alloying elements (Belov et al., 2005; Manasijević et al., 2011; Manasijevic, 2012; Manasijevic et al., 2013; Manasijević et al., 2014).

The alfin bonding process begins with the growth of an $\mathrm{Al}$ alloy intermetallic surface layer on the ring carrier by immersion of the ring carrier in a molten $\mathrm{Al}$ alloy bath. The alfin bond is a real bond, which has a chemical composition close to $\mathrm{Fe}_{\mathrm{x}} \mathrm{Al}_{\mathrm{y}}$ and is formed by the $\mathrm{Fe}$ and $\mathrm{Al}$ alloy.

Characterization by optical and SEM microscopy, a qualitative analysis of the phases in the intermetallic bonding layer was conducted by EDS scanning electron microscopy. Figure 5a shows a SEM analysis while. Figure 5b shows an EDS mapping of all the elements in the intermetallic bonding layer. Figures $5 \mathrm{c}$ to $5 \mathrm{f}$ show the EDS mapping of other important elements.

Figure 6 shows that the EDS analysis detected the presence of an intermetallic bonding layer (the $\mathrm{FeAl}_{3}$ intermetallic phase was formed). 

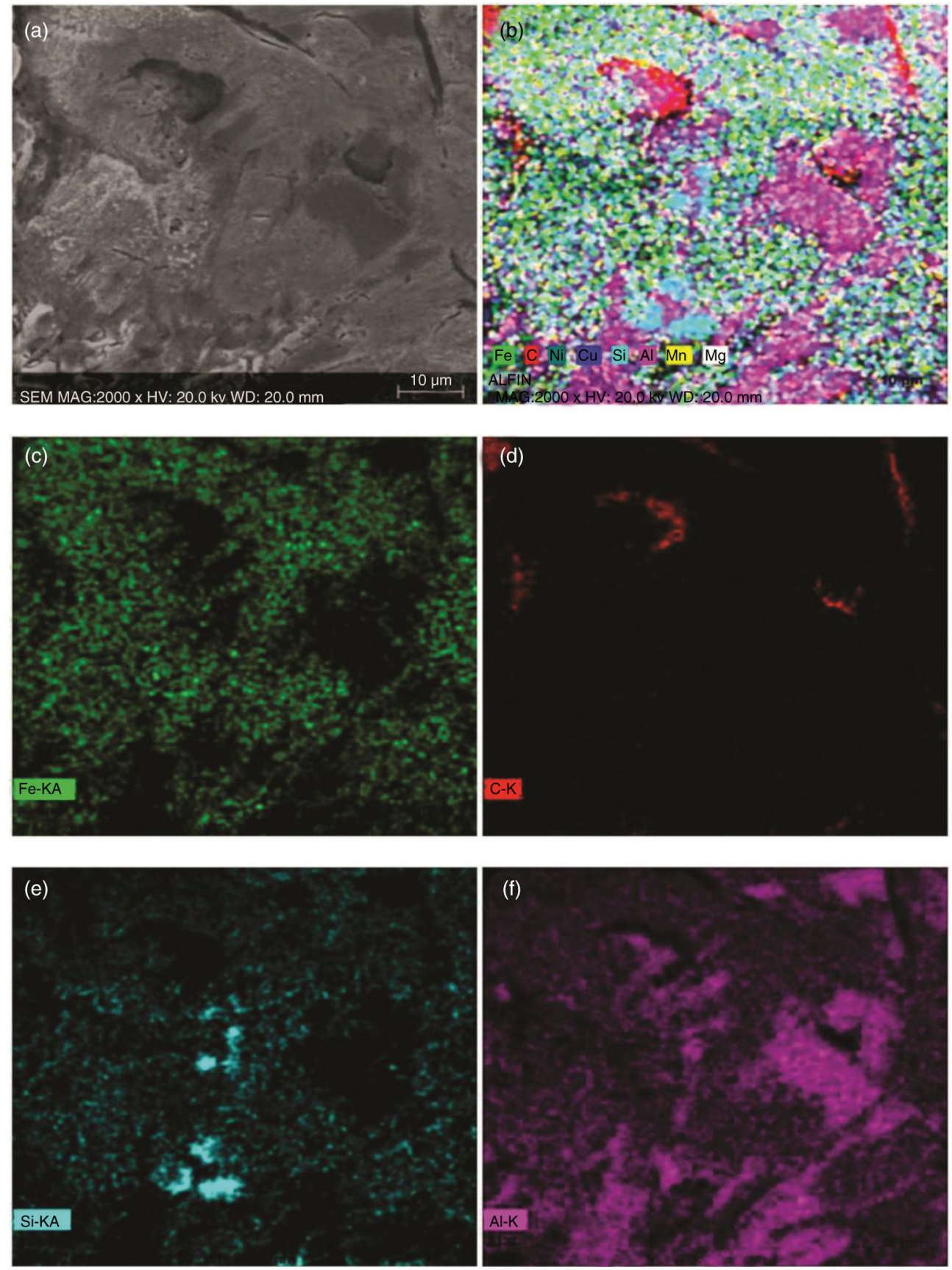

FIgURE 5. The intermetallic bonding layer: a) SEM; b) EDS mapping of all elements and EDS mapping; c) Fe; d) C; e) Si and f) Al.

In accordance with the the Fe-Al binary phase diagram, other phases can be expected in addition to the identified $\mathrm{FeAl}_{3}\left(\mathrm{Fe}_{2} \mathrm{Al}_{5}\right)$ phase (Kattner, 1990).

\section{CONCLUSIONS}

Based on the analysis of the experimental test results presented in this paper, it could be concluded that:

- A good metallic bond can be formed between the aluminum piston alloy and austenitic cast iron.
- Average the thickness of the intermetallic layer in this case is $32.39 \mu \mathrm{m}$.

- The EDS analysis detected that $\mathrm{FeAl}_{3}$ and $\mathrm{Fe}_{2} \mathrm{Al}_{5}$ intermetallic phases were formed.

The results presented in this paper are only an introduction to further ongoing research related to the phase composition of the intermetallic bonding layer studied by the XRD analyses and the testing of the mechanical strength of the bond. 


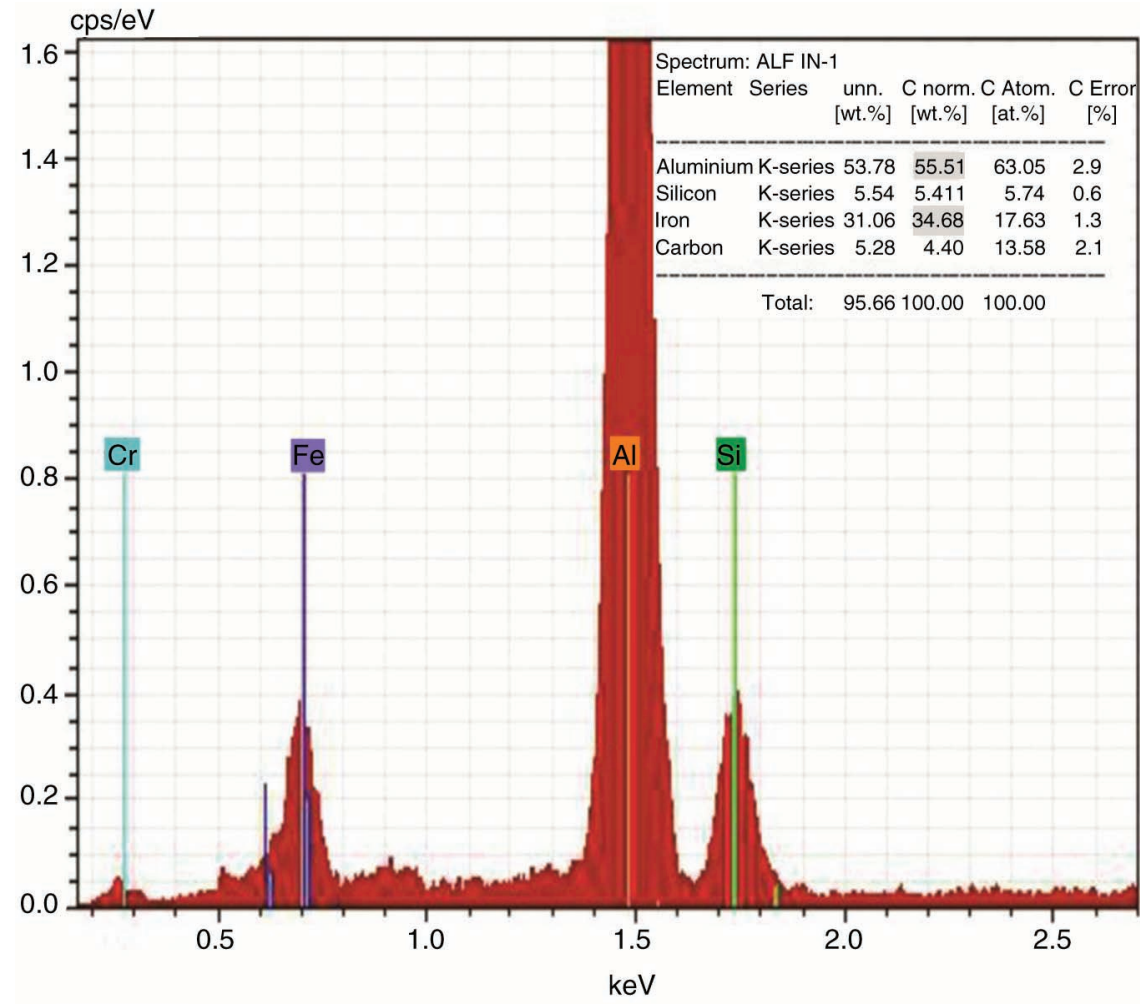

FIGURE 6. EDS identification of $\mathrm{FeAl}_{3}$.

\section{ACKNOWLEDGMENTS}

The research presented in this paper was funded by the Ministry of Education and Science of the Republic of Serbia.

\section{REFERENCES}

Acar, A.F., Ozturk, F., Bayrak, M. (2010). Effects of variations in alloy content and machining parameters on the strength of the intermetallic bonding between a diesel piston and a ring carrier. Mater. Technol. 44 (6), 391-395.

Belov, N.A., Eskin, D.G., Avxenieva, N.N (2005). Constituent phase diagrams of the Al-Cu-Fe-Mg-Ni-Si system and their application to the analysis of aluminium piston alloys. Acta Mater. 53 (17), 4709-4722. http://dx.doi.org/10.1016/j. actamat.2005.07.003.

Engine Australia Pty Ltd. (2012). Alfin (Ni-Resist) Ring groove inserts. Service Enginering Bulletin.

Kattner, U.R. (1990). Binary alloy phase diagrams. Massalski, T.B., (Ed.). ASM International, Materials Park, OH, p. 147.

Manasijevic, S., Radisa, R., Markovic, S., Raic, K., AcimovicPavlovic, Z. (2009). Implementation of the infrared thermography for thermo-mechanical analysis of the AlSi cast piston.
Prakt. Metallogr. 46 (11), 565-579. http://dx.doi.org/ 10.3139/147.110015.

Manasijević, S., Radiša, R., Marković, S., Aćimović-Pavlović, Z., Raić, K. (2011). Thermal analysis and microscopic characterization of the piston alloy AlSi13Cu4Ni2Mg. Intermetallics 19 (4), 486-492. http://dx.doi.org/10.1016/j. intermet.2010.11.011.

Manasijevic, S. (2012). Aluminum Piston Alloys, Radiša, R. (Ed.), LOLA Institute Belgrade, Serbia.

Manasijevic, S., Acimovic-Pavlovic, Z., Raic, K., Radisa, R. Kvrgic, V. (2013). Optimisation of cast pistons made of Al-Si piston alloy. Int. J. Cast. Metal. Res. 26 (5), 255-261. http://dx.doi.org/10.1179/1743133612Y.0000000007.

Manasijević, S., Dolić, N., Raić, K., Radiša, R. (2014). Identification of Phases Formed by $\mathrm{Cu}$ and $\mathrm{Ni}$ in Al-Si Piston Alloys. La Metallurgia Italiana 106 (3), 13-19.

Worden, J.A., Starr, G.L., Chen, Y.-Ch. (2000). Formation of a graphite-free surface in a ferrous material to produce an improved intermetallic bond. Patente US6127046 A

Willcox, M. (2000). Ultrasonic inspection equipment for Al-Fin insert diesel pistons. Insight NDT equipment Ltd. Available at. http://www.insight-ndt.com/papers/products/ut001.pdf. (accessed June/2015)

Viala, J.C., Peronnet, M., Barbeau, F., Bosselet, F., Bouix, J. (2002). Interface chemistry in aluminium alloy castings reinforced with iron base inserts. Compos. Part A-Appl. S. 33 (10), 1417-1420. http://dx.doi.org/10.1016/S1359-835X(02)00158-6. 